\title{
Recruitment of Seemingly Overeducated Personnel: Insider-Outsider Effects on Fair Employee Selection Practices*
}

\author{
Oliver Fabel ${ }^{\dagger}$ \\ Department of Business Administration \\ University of Vienna, Austria \\ Razvan Pascalau ${ }^{\ddagger}$ \\ Department of Economics, Finance \& Legal Studies \\ University of Alabama, USA
}

May 15, 2008

*We thank M. Rauber and A. Flossmann, Konstanz, and J. Lee, Alabama, as well as participants of the 10th Colloquium on Personnel Economics 2007 at the University of Tübingen, and of research seminars at the universities of Alabama, Konstanz, Southern Mississippi, Vienna, and Wuppertal for very helpful comments on earlier versions of this paper.

${ }^{\dagger}$ Prof. Dr. Oliver Fabel, University of Vienna, Faculty of Business, Economics and Statistics, Department of Business Administration, Chair for International Personnel Management, Brünner Str. 72, 1210 Vienna, Austria; Tel: 43-1-4277-38161, Fax: 43-1-4277-38164, E-mail: oliver.fabel@univie.ac.at.

${ }^{\ddagger}$ Razvan Pascalau, PhD, Department of Economics, Finance \& Legal Studies, Culverhouse College of Commerce and Business Administration, University of Alabama, 200 Alston Hall Box 87-0224, Tuscaloosa, AL, 35487, USA; Tel.:+1-205-348-7592; E-Mail: rpascala@cba.ua.edu. 


\begin{abstract}
We analyze a standard employee selection model given two institutional constraints: first, professional experience perfectly substitutes insufficient formal education for insiders while this substitution is imperfect for outsiders. Second, in the latter case the respective substitution rate increases with the advertised minimum educational requirement. Optimal selection implies that the expected level of formal education is higher for outsider than for insider recruits. Moreover, this difference in educational attainments increases with lower optimal minimum educational job requirements. Investigating data of a large US public employer confirms both of the above theoretical implications. Generally, the econometric model exhibits a "good fit".
\end{abstract}

Keywords: employee selection, overeducation, adverse impact, insiders vs outsiders.

JEL-Classifications: M51 (Firm Employment Decisions; Promotions), J53 (LaborManagement Relations; Jurisprudence), J78 (Labor Discrimination; Public Policy), I21 (Analysis of Education). 


\section{Introduction}

Our analysis augments the standard textbook "utility analysis" ${ }^{1}$ of personnel selection to include three predictors: educational attainment, professional experience, and test scores. To account for fair employee selection rules, we further assume that the firm substitutes professional experience for formal education. Yet, since job requirements and their corresponding descriptions always contain some firm-specific elements, this substitution is less than perfect for applicants from outside the firm. Due to increased legal risk, the respective substitution rate applied to outsider applications then increases with higher minimum educational requirements.

With informative signals the probability of being hired monotonically increases in all three signal values. However, given the constraints above, the expected educational attainment of outsider recruits exceeds that of current employees. Further, the wedge between the two groups' expected educational levels widens with decreasing minimum educational requirements. We then subject this selection model to empirical testing using a data set supplied by a large US public employer. The data allows to control for a number of characteristics that are specific to a particular job-opening, selection process, and individual applicant. The empirical analysis strongly supports our theoretical predictions.

While every US employer is generally free to employ individuals at his will, qualification requirements should be reasonable to avoid disparate impact charges under Title VII of the Civil Rights Act of $1964^{2}{ }^{2}$ To the extent that members of minority groups, women, or disabled individuals are socially excluded from formal education or professional training such requirements could else be ruled excessively restrictive - i. e. set to preclude successful applications from these groups. ${ }^{3}$ In such cases, the Civil Rights Act of 1991 introduces the right to a jury trial and to rely on statistical information as evidence. Moreover, punitive damages in addition to back-pay increase the potential costs

\footnotetext{
${ }^{1}$ Holling (1998) provides a survey of model structures that originated in assessment psychology. Schmidt and Hunter (1998) discuss further developments of this approach.

${ }^{2}$ See Carlson (2005, p. 126 - 132) for an account of origins and consequences of non-discrimination law and precedence court decisions concerning the employee selection process.

${ }^{3}$ In the original case - see Griggs v. Duke Power Co., 401 U.S. 424 (1971) - the company required a highschool diploma and a certain score on a general aptitude test to qualify for internal promotion. The court found that these requirements disparately impact ethnic minority groups. Specifically, AfricanAmericans were less likely to hold a highschool degree and averaged lower test scores and were, therefore, selected at a much a lower rate.
} 
per case. ${ }^{4}$ Since charges can concern wrongful non-hirings as well as non-promotions, this legal risk applies to all employee selection processes within firms. ${ }^{5}$

Thus, the Equal Employment Opportunity Commission (EEOC) advises to state qualification requirements in terms of necessary skills and abilities rather than formal educational degrees or years of experience. ${ }^{6}$ This advice meets with a second set of rules that is rooted in the employer's duty to provide job security and career development: ${ }^{7}$ fair selection standards should be alternatively phrased in terms of formal educational requirements and substitute professional experience criteria. In this respect, public sector employees are additionally covered by the Fourteenth Amendment right to Equal Protection. ${ }^{8}$ The federal government itself therefore commits to a set of rules laid out in the Operating Manual: Qualification Standards for General Schedule Positions. ${ }^{9}$ This manual lists the required educational degree and equivalent professional experience for specified hierarchical positions. ${ }^{10}$

The disparate impact issue has received repeated attention by economists. ${ }^{11}$ Yet, such analyses typically address the effects on groups that are protected under this legislation. To our knowledge, only Oyer and Schaefer (2002) so far show that, since population groups differ in their propensities to press charges, the Civil Rights Act of 1991 induces significant distributional consequences as well. However, the risk of disparate impact suits is also job-specific: first, the standards themselves must be reasonable such as not to exclude qualified individuals. Second, professional experience gained in similar - typically, reflecting career tracks, hierarchically inferior - positions within the firm can substitute for a lack of formal education. Jointly these two sets of institutional constraints then induce a differential treatment of insider and outsider applications.

Since the seminal work of Freeman (1976) and Duncan and Hoffman (1981), nu-

\footnotetext{
${ }^{4}$ Oyer and Schaefer (2002).

${ }^{5}$ See Gutman $(2003,2004)$ for an overview of precedence cases and court decisions.

${ }^{6}$ See section 15-IX "Proactive Prevention" EEOC (2006).

${ }^{7}$ Clardy (2003).

${ }^{8}$ See Carlson (2005, p. 753 - 756).

${ }^{9}$ This manual is updated and published (without publication date) by the US Office of Personnel Management, Washington D. C.

${ }^{10}$ The New York State Department of Civil Services' view of Knowledge-Skill-Ability-Based Minimum Qualifications - see Martin (2005) - provides an interesting second example since it sets out to define an "equivalence equation" to compute substitute professional experience requirements.

${ }^{11}$ Respective contributions to annual meetings of the American Economic Association include Welch (1981), Ashenfelter and Oaxaca (1987), Abram (1993), Coates and Loury (1993), and Betsey (1994).
} 
merous empirical studies report that overeducation increases wages and employment probabilities. Also, this effect is stronger for unskilled or lower-skilled than for skilled jobs. ${ }^{12}$ However, explanations are mostly labor-market oriented. ${ }^{13}$ The career mobility approach developed by Sicherman and Galor (1990) constitutes the notable exception: responding to their firm's human resources development strategy, individuals enhance their career progress by accepting "underqualified work" in early career stages. So far, only Groeneveld and Hartog (2004) provide an empirical test. Investigating jobs sheltered in a protected internal labor market, they conclude that the overeducation effect on wages reflects such strategic behavior.

Our contribution is then threefold: first, we empirically confirm the existence of an overeducation effect on hiring probabilities. However, since this effect is confined to outsider recruits, it does not support the career mobility argument. Second, we therefore provide a simple but novel model of personnel selection that explicitly accounts for the institutional constraints above. Since these constraints restrict the use of informative signals, the firm's outsider recruits are only seemingly overeducated - i.e. without the constraints the firm would have advertised higher standards. Hence, third, our arguments highlight the informational inefficiency induced by the threat of disparate impact charges.

The remainder of this paper is organized as follows: the next section develops the theoretical model and derives testable hypotheses. Section 3 provides a description of the data, develops the econometric approach, and reports our empirical findings. The paper concludes with a summary and discussion - the latter also addressing new regulations currently emerging in the European educational systems.

\footnotetext{
${ }^{12}$ See the survey included in Groot and Maasen van den Brink (2000).

${ }^{13}$ Hence, emphasizing inefficient investment in ability signals, arguments derived from Spence's (1973) theory of labor market signaling and Thurow's (1975) theory of job competition compete with Sattinger's (1993) assignment theory. See, for instance, Hartog (2000), Bauer (2002), and Chevalier (2003) for literature surveys and respective applications.
} 


\section{The model}

\subsection{Basic assumptions and notations}

We have conducted extensive interviews within the firm to verify the following sequence of screening and selection activities: all applicants who pass the advertised educational and professional selection criteria are pooled and subjected to the same set of job-specific ability tests. These tests always include job interviews with and formally evaluated by the Department of Employment ( $D o E)$. Conditional on the job type, other tests of cognitive abilities and/or non-cognitive skills may be added. Appreciating the results of these tests, DoE makes its hiring choices to be implemented by Human Resources $(H R)$.

For theoretical analysis then, let on-the-job ability $a$ be identically and independently distributed $N\left(\mu, \sigma_{a}^{2}\right)$ over the two populations of applicants denoted insiders and outsiders. Further, the degree of formal schooling $s$, professional experience $x$, and potential test scores $z$ are known to be identically, independently, and standard normally distributed over these two populations. As usual, $\Phi(y)$ and $\phi(y), y \in\{s, x, z\}$, denote the standard normal distribution and density functions.

$H R$ has carried out pre-tests to validate that

$$
a=\alpha+\beta_{s} s+\beta_{x} x+\beta_{z} z+\varepsilon
$$

where $\varepsilon \sim N\left(0, \sigma_{\varepsilon}^{2}\right)$ is a measurement error with $\operatorname{Cov}(\varepsilon, y)=0$ for $y \in\{s, x, z\}$. Realistically, the predictors are correlated. For instance, holding age constant, the duration of formal education and professional experience should be negatively correlated. ${ }^{14}$ However, assuming stochastic independence between signals serves to identify the economic mechanisms driving the outcome of this process of screening and testing. Hence, we assume that $\operatorname{Cov}(s, x)=\operatorname{Cov}(s, z)=\operatorname{Cov}(x, z)=0$.

In contrast, $r_{a y} \geq 0$ denotes the coefficient of correlation between ability and the predictor $y, y \in\{s, x, z\}$. Then, $\alpha=\mu$ and $\beta_{y}=\frac{r_{a y} \sigma_{a}}{\sigma_{y}}$. To (significantly) economize on space and notation, we assume that $r_{a x}=r_{a s}=\rho$ in the following. Hence, the two signals concerning educational and professional qualifications derived at no costs from the applicant's documents serve equally well as ability predictors. Further simplifying notations, $r_{a z}=r$.

\footnotetext{
${ }^{14}$ Empirically, we can control for this effect by entering age as an explanatory variable. See Anderson et al. (2004) concerning the interaction of commonly used predictors.
} 
$H R$ is mainly concerned with minimizing the legal costs. Specifically, our firm being a public employer observes that screening applications on grounds of formal education bears the risk of disparate impact charges. Although the firm encourages its employees to enroll in further education programs and obtain formal degrees, it therefore also accepts that professional experience can substitute for lacking educational degrees.

Taken to its theoretic extreme, we assume that applicants from within the firm cannot be screened out if the sum of their educational and professional achievements exceeds the sum of the respective two minimum requirements. Thus, suppose that the job advertisement requires minimum educational qualification $S$ and professional experience $X$. Let $\omega^{I} \equiv s+x$ and $\Omega \equiv S+X$. Note that $\omega^{I} \sim N(0,2)$ and denote the respective distribution and density functions by $\Psi^{I}\left(\omega^{I}\right)$ and $\psi^{I}\left(\omega^{I}\right)$. Also, all applicants whose test score satisfies $z \geq Z$ will actually be hired. The expected ability of insider recruits can then be derived as

$$
\begin{gathered}
E^{I}\{a ; S, X, Z\}= \\
\mu+\sigma_{a}\left[r_{a s} E\left\{s \mid \omega^{I} \geq \Omega\right\}+r_{a x} E\left\{x \mid \omega^{I} \geq \Omega\right\}+r_{a z} E\{z \mid z \geq Z\}\right]= \\
\mu+\sigma_{a}\left[\sqrt{2} \rho \int_{\Omega}^{\infty} \omega^{I} \frac{d \Psi^{I}\left(\omega^{I}\right)}{\left(1-\Psi^{I}(\Omega)\right)}+r \int_{Z}^{\infty} z \frac{d \Phi(z)}{(1-\Phi(Z))}\right] .
\end{gathered}
$$

In principle, the substitution rule above applies to all applications. Yet, job requirements and their corresponding descriptions always contain some firm-specific elements. Hence, the legal risk of screening on grounds of formal education is lower when dealing with applications from outside the firm. We therefore assume that the substitute professional experience claimed by outsiders is discounted. Given the argument that educational standards may conceal discriminatory practises, the rate of substitution is then perceived as increasing with minimum educational requirements. ${ }^{15}$

Thus, let $\tau \in(0,1)$ denote the "discount" factor measuring the fraction of an outsider's documented professional experience that qualifies for the job opening. ${ }^{16}$ To focus on the informational aspects of the screening process, we assume that this "discounting"

\footnotetext{
${ }^{15}$ To put it more blankly, if a gardener's job would be advertised to require a PhD in botanics, every less educated member of a socially disadvantaged group who could prove to have experience in lawn mowing could successfully claim to have been discriminated.

${ }^{16}$ Obviously, it would be more adequate to assume that an individual outsider's professional experience is subject to a discount factor $t$ where $t$ constitutes a random variable with expected value $\tau$. Thus, accounting only for the expected value of discounting implies that the distribution of $t$ is independent of the individual's signal profile $(s, x, z)$.
} 
of an outsider's professional experience only affects the possibility to enforce the screening criteria $S$ and $X$. As discussed above, we specifically assume that $\tau=\tau(S)$, with $\tau^{\prime}(S)>0$ and $\lim _{S \rightarrow \infty} \tau(S)=1$.

Letting $\omega^{O}=s+\tau(S) x$, note that $\omega^{O} \sim N\left(0,1+(\tau(S))^{2}\right)$. Then, denote the respective distribution and density functions by $\Psi^{O}\left(\omega^{O} ; \tau(S)\right)$ and $\psi^{O}\left(\omega^{O} ; \tau(S)\right)$. The expected ability of outsider recruits can thus be obtained as

$$
\begin{gathered}
E^{O}\{a ; S, X, Z\}= \\
\mu+\sigma_{a}\left[r_{a s} E\left\{s \mid \omega^{O} \geq \Omega\right\}+r_{a x} E\left\{x \mid \omega^{O} \geq \Omega\right\}+r_{a z} E\{z \mid z \geq Z\}\right]= \\
\mu+\sigma_{a}\left[\frac{2 \rho}{\sqrt{1+(\tau(S))^{2}}} \int_{\Omega}^{\infty} \omega^{O} \frac{d \Psi^{O}\left(\omega^{O} ; \tau(S)\right)}{\left(1-\Psi^{O}(\Omega ; \tau(S))\right)}+r \int_{Z}^{\infty} z \frac{d \Phi(z)}{(1-\Phi(Z))}\right] .
\end{gathered}
$$

Obviously, the above calculations of expected abilities demand that both groups of applicants are sufficiently large. For simplicity, we further assume that they are of identical size $N$. Given that there are $M$ openings, the recruitment process must then ensure that

$$
(1-\Phi(Z))\left[\sum_{A=I, O}\left(1-\Psi^{A}(\Omega)\right)\right]=\frac{M}{N}
$$

where $\frac{M}{N}<1$. DoE's objective, implemented by $H R$, is to maximize the expected ability

$$
E^{F}\{a ; S, X, Z\}=\frac{\sum_{A=I, O}\left(1-\Psi^{A}(\Omega)\right) E^{A}\{a ; S, X, Z\}}{\sum_{A=I, O}\left(1-\Psi^{A}(\Omega)\right)}
$$

of its new recruits net of the costs $C$ associated with the ability tests. Following the literature on testing for recruitment, these costs are fixed and reflect $H R$ 's choice of the test design. No such costs must be incurred if recruitment decisions are based only on the educational and professional information documented by the applicants themselves.

\subsection{Screening and testing with homogeneous groups of applicants}

Focussing on recruiting from only one group of applicants highlights the economic mechanism governing the particular recruitment process. Hence, suppose that there are only internal applications and set $\Psi^{O}(\Omega)=1$ in (5) and (4) above. The respective Lagrange- 
function can be derived as

$$
\begin{aligned}
\mathrm{E}^{I}= & \eta(Z)\left[E^{I}\{a ; S, X, Z\}-C\right]+(1-\eta(Z))\left(\lim _{Z \longrightarrow-\infty} E^{I}\{a ; S, X, Z\}\right) \\
& -\lambda^{I}\left[(1-\Phi(Z))\left(1-\Psi^{I}(\Omega)\right)-\frac{M}{N}\right]
\end{aligned}
$$

where

$$
\eta(Z)=\left\{\begin{array}{cc}
1 & \text { if } \Phi(Z) \in(0,1] \\
0 & \text { if } \Phi(Z)=0
\end{array}\right.
$$

denotes an indicator function that captures the opportunity cost nature of $C$.

The first-order conditions can be rearranged to yield:

$$
\begin{gathered}
\eta(Z): E^{I}\{a ; S, X, Z\}-C-\lim _{Z \longrightarrow-\infty} E^{I}\{a ; S, X, Z\}\left\{\begin{array}{l}
= \\
\leq
\end{array}\right\} 0, \\
\text { if } \Phi(Z)\left\{\begin{array}{l}
\geq \\
=
\end{array}\right\} 0 ; \\
Y \in\{S, X\}: \quad \lambda^{I}(1-\Phi(Z))+\frac{\eta(Z)}{\psi^{I}(\Omega)} C= \\
\quad \frac{\sigma_{a} \sqrt{2} \rho}{\left(1-\Psi^{I}(\Omega)\right)}\left[\Omega-\int_{\Omega}^{\infty} \omega^{I} \frac{d \Psi^{I}\left(\omega^{I}\right)}{\left(1-\Psi^{I}(\Omega)\right)}\right] \\
Z: \quad \lambda^{I}\left(1-\Psi^{I}(\Omega)\right)= \\
\frac{\sigma_{a} r}{(1-\Phi(Z))}\left(Z-\int_{Z}^{\infty} z \frac{d \Phi(z)}{(1-\Phi(Z))}\right), \text { if } \eta(Z)=1 .
\end{gathered}
$$

These conditions immediately reveal two important properties: first, according to (9), $H R$ will never set separate educational and professional minimum requirements if applications can only come from within the firm. Second, only if $H R$ decides on additional testing, the optimum recruitment policy balances the marginal returns from setting application and testing standards. Otherwise, expected ability is simply determined by choosing $\Omega$ such as to satisfy (4) for $\Phi(Z)=0$.

Investigating (8) then reveals

$$
\begin{gathered}
\Delta E^{I} \equiv E^{I}\{a ; S, X, Z\}-C-\lim _{Z \longrightarrow-\infty} E^{I}\{a ; S, X, Z\}= \\
-C+\sigma_{a} r \int_{Z}^{\infty} z \frac{d \Phi(z)}{(1-\Phi(Z))}-\sigma_{a} \sqrt{2} \rho \int_{\Omega}^{\widetilde{\Omega}} \omega^{I} \frac{d \Psi^{I}\left(\omega^{I}\right)}{\Psi^{I}(\widetilde{\Omega})-\Psi^{I}(\Omega)}
\end{gathered}
$$


where $\widetilde{\Omega}$ is defined by $\left(1-\Psi^{I}(\widetilde{\Omega})\right)=\frac{M}{N}$. Accounting for (4) given the above assumption that $\Psi^{O}=1, \lim _{Z \longrightarrow-\infty} \Delta E^{I}=-C<0$. Thus, additional testing can is optimal if the respective costs are low. Also, the coefficient of correlation $r$ between ability and the test score should be large relative to $\rho$.

Job interviews are likely to qualify in this respect. ${ }^{17}$ For the remainder, we will therefore assume such an interior solution. This solution then implies

$$
\frac{r\left[Z-\int_{Z}^{\infty} z \frac{d \Phi(z)}{(1-\Phi(Z))}\right]}{\rho\left[\Omega-\int_{\Omega}^{\infty} \omega^{I} \frac{d \Psi^{I}\left(\omega^{I}\right)}{\left(1-\Psi^{I}(\Omega)\right)}\right]}=1-\frac{C\left(1-\Psi^{I}(\Omega)\right)}{\psi^{I}(\Omega) \sigma_{a}\left[\Omega-\int_{\Omega}^{\infty} \omega^{I} \frac{d \Psi^{I}\left(\omega^{I}\right)}{\left(1-\Psi^{I}(\Omega)\right)}\right]}>1 .
$$

As expected, the testing costs induce a distortion: selection according to test scores is "over-restrictive".

Setting $\Psi^{I}(\Omega)=1$ in (5) and (4) then allows to characterize the alternative scenario of hiring only from a pool of outsiders. Switching superscripts, the first-order conditions with respect to $\eta(Z)$ and $Z$ then restate (8) and (10) from above. Yet, (9) is replaced by,

$$
\begin{gathered}
X: \quad \lambda^{O}(1-\Phi(Z))+\frac{\eta(Z)}{\psi^{O}(\Omega)} C= \\
\frac{2 \sigma_{a} \rho}{\left(1-\Psi^{O}(\Omega)\right) \sqrt{1+(\tau(S))^{2}}}\left[\Omega-\int_{\Omega}^{\infty} \omega^{O} \frac{d \Psi^{O}\left(\omega^{O}\right)}{\left(1-\Psi^{O}(\Omega)\right)}\right] \\
S: \quad \lambda^{O}(1-\Phi(Z))+\frac{\eta(Z)}{\psi^{O}(\Omega)} C= \\
\frac{2 \sigma_{a} \rho}{\left(1-\Psi^{O}(\Omega)\right) \sqrt{1+(\tau(S))^{2}}}\left[\Omega-\int_{\Omega}^{\infty} \omega^{O} \frac{d \Psi^{O}\left(\omega^{O}\right)}{\left(1-\Psi^{O}(\Omega)\right)}\right] \\
+\frac{2 \sigma_{a} \rho \tau^{\prime}(S) \tau(S)}{\psi^{O}(\Omega)\left(1+(\tau(S))^{2}\right)^{\frac{3}{2}}} \int_{\Omega}^{\infty} \omega^{O} \frac{d \Psi^{O}\left(\omega^{O}\right)}{\left(1-\Psi^{O}(\Omega)\right)}
\end{gathered}
$$

where we have made use of the properties of the normal distribution to obtain (14).

Taking the limits $S \rightarrow \infty$ of the RHS of (13) and (14), this corner solution violates (4) since all applicants would be screened out. Further, taking the respective limits $S \rightarrow-\infty$

\footnotetext{
${ }^{17}$ See e. g. Dakin and Armstrong (1989) and, distinguishing selection criteria in great detail, Robertson and Smith (2001).
} 
implies that the expected signal values are zero. Hence, the applicants' documents would not be used for screening at all. However, since this information is costless for the firm, this corner solution can also be ruled out. Again, an interior solution is ensured if it is optimal to test the applicants. The preceding arguments then imply that this solution must be characterized by $0<\tau(S)<1$.

Comparing (13) and (14) with (9) reveals that the interior solution implies distinctly separate minimum educational and professional experience requirements in the outsiderrecruitment case. From a purely informational economics perspective, "discounting" the professional experience of outsiders increases the precision of the signal $\omega^{O}$ which is subjected to the cut-off criterion $\Omega$.

Two effects then determine optimal precision: first, as $\tau(S)$ decreases, the two signals $x$ and $s$ contained in $\omega^{O}$ are increasingly used separately to predict on-the-job ability. Yet, the positive effect of this signal separation on the precision of $\omega^{O}$ is traded-off against the fact that professional experience also receives less weight as a predictor of ability. In the extreme, for $\tau(S)=0$, experience would not be used for screening at all.

\subsection{Recruiting from two independent pools of insiders and outsiders}

Since the firm is subject to mandatory public job advertisements, $H R$ organizes the actual recruitment process to maximize (5) subject to (4). Yet, characterizing the solution does not add further analytic insights. The respective first-order conditions with respect to the minimum educational and professional experience requirements, $S$ and $X$, merely contain weighted sums of the terms in (13), (14), and (9). The weights are given by $\sum_{A=I, O} \psi^{A}(\Omega) / \sum_{A=I, O}\left(1-\Psi^{A}(\Omega)\right)$.

Hence, the characterizations above carry over in the sense that, if - given the costs of testing - the test scores are used for selection, the solution balances the marginal returns from using all three signals for recruitment. Separate educational and professional experience standards will then be advertised but only enforced in screening outsider applications. These analytic conclusions imply the following hypotheses for empirical testing:

H1: Outsider recruits are characterized by higher educational levels than insider recruits. 
Since insider applications resemble the current structure of educational attainments in the firm's labor force, new employees therefore appear to be overeducated. However, they are only seemingly overeducated: suppose the threat of disparate impact charges would not constrain $H R$ in advertising and enforcing educational requirements. Then, it would require higher educational standards to economize on the respective signal value. The insider-outsider difference thus reflects that $H R$ cannot use this signal when dealing with insiders.

Further, recall that lower minimum educational requirements $S$ ceteris paribus increase the possibility of "discounting" the professional experience of outsiders. ${ }^{18}$ This policy is optimal because it increases the precision of the screening process. Since the effect only applies to outsider applications, recruiting for jobs that are advertised to require rather low educational degrees yields relatively more "overeducation" of outsider recruits. Hence, it also follows:

H2: The overeducation effect on the group of outsider recruits increases with lower minimum educational standards advertised by the firm.

\section{$3 \quad$ Empirical analysis}

\subsection{The data}

In May 2003, the firm - a large US public employer - introduced an online recruiting system. Starting with this date, all job applicants are required to (also) file an electronic application and obtain log-in user-names and passwords. Our data then covers the period from the introduction of this system to February 2006. During this phase $H R$ assigned a team to provide assistance for potential applicants. The data is further restricted to rank-and-file employee and laborer positions; we exclude recruitment processes to fill executive positions. Our data set comprises 33780 observations of individuals who (a) filed complete applications during this time-span and (b) entered a recruitment process that reached a final decision by the end of our observation period. There are 1244 of such processes (see Table 1).

\footnotetext{
${ }^{18}$ Within the current framework, the typical "ceteris paribus" clause particularly implies that other job characteristics (technical vs. administrative, superior vs. inferior hierarchical position etc.) are held constant.
} 
The data set contains information concerning the educational attainments of all candidates. All possible US degrees - i.e. doctorate, master, bachelor, some college education, high school degree, highschool equivalent degree (GED), and only some high school education - can be found among both applicants and recruits (see Table 2). The data further contains the applicant's work experience, age, gender, race, and the recruitment channel by which she had been attracted. Each application is linked to a job-opening for which the data set provides the expected date of commencing work, position title, DoE, and type of appointment (Job Type). The latter ranges from 1 for Contingent/On-Call Labor (no benefits) to 6 for Regular/Full-Time Employee (eligible for benefits).

Upon our request, $H R$ also supplied the respective advertised required minimum levels of education, the Equal Employment Opportunity (EEO) code numbers which increase in steps of 10 points from 10 (executive, administrative and managerial positions) to 70 (service and maintenance positions), the Fair Labor Standards Act status (FLSA) which takes on the value 1 if the job is exempt (no overtime pay) and zero otherwise, and the workplace score (Grade). The latter reflect the necessary skills and experience, the complexity of the tasks and creativity required in exercising them, the job's impact on the firm's mission, exposure to internal and external contacts, the degree of discretion in decision making, physical stress, and working conditions. The weights associated with these factors are determined consensually by $H R$ and the $D o E$ prior to advertising the job opening. Calculated as a weighted sum of these factors, the score determines the compensation range.

Defining overeducation as possessing a higher than the advertised educational degree, Table 3 reveals that the majority of the recruits - i.e. 58\% - were (formally) overeducated, while $34 \%$ actually possessed just the minimum required degree (adequately educated). Applications that were forwarded by direct contact from a $D o E(D C D)$ or other internal reference $(I R)$ are classified to reflect the insider status. They constitute $11.4 \%$ of all applications. All other recruitment channels - i.e. initiated by web-based job posting board, the firm's own website, newspaper advertisements $(N w A d)$, job notices sent to colleges or universities $(J N U)$ or to the state employment office $(S E O)$, and other $(O R C)$ - in sum define the outsider status.

Combining the first two of the above as web-recruitment channels ( WebRc), they account for those $77 \%$ of the applications which doubtlessly come from outside the firm (see Table 3). Insiders (IREDCD) then form the largest group among recruits 
who are undereducated regarding their educational attainments. In contrast, outsiders constitute the largest group among the overeducated recruits. This observation already suggests that insider and outsider applications receive rather different appraisals during the recruitment process.

\subsection{Definitions of variables and OLS-estimation}

The dependent variable Status in the regression reported in Table 4 takes on the value 1 if the applicant is hired and zero otherwise. Characterizing the particular job opening, Grade, the EEO code number, the FLSA status variable, and Job Type serve as explanatory variables. The characteristics of the recruitment processes are captured by the total number of job-candidates (Applications) per job. In addition, the number of applications which used the same recruitment channel (Appl.'s $R c$ ) reflects the individual's competitive environment.

As explained above, an insider application is defined by the use of internal references. Including the recruitment channel used by a particular outsider applicant then serves to examine whether there exists a dominant form of attracting successful candidates from outside the firm. Other variables characterizing the individual applicant are Age, Sex (equal to 1 if the applicant is male), professional Experience, and the minority status (Non-White). ${ }^{19}$ Unfortunately, the data only allows to identify whether the individual possesses (1) or does not possess (0) adequate professional experiences as judged by $H R$. As usual, we also include the square of the individual's age to allow for a non-linear age-productivity profile.

Clearly, the variables reflecting the applicant's educational background are of key interest. The variable Education ranges from 0 for completed first grade to 19 for a doctorate degree. This coding thus mirrors the individual's time spent in formal education. To capture a possible non-linear education-productivity relationship we also include the square of this variable. Exact Qual takes on the value 1 if the applicant is just qualified relative to the advertised minimum educational level. Over Qual and Less Qual then indicate over and undereducated applicants, respectively. The reference category is Over Qual. Given our model above, the insider effect on the hiring probability is reflected in professional experience substituting for a lack of formal education. Thus, we include the respective interaction variables Exp Ins. and Educ Ins. between Experience

\footnotetext{
${ }^{19}$ More detailed ethnic classifications did not prove statistically significant.
} 
and Education and the insider status.

Table 4 shows the results from performing a simple OLS regression. The probability to be recruited is lower for non-whites and older applicants where the latter effect appears to level out. Higher hiring probabilities for women likely reflect the overall dominance of administrative jobs in the sample. The negative sign for Job Type also meets our expectations since the value of this variable decreases with more attractive hierarchical positions. More competition for the job - as measured by Applications and Applicant's $R c$ - decreases the probability to be hired. Among the recruitment channels for outsiders, web-based applications exhibit a strong positive impact, while being sent by the state employment agency decreases the hiring probability. Clearly, the former signals more and the latter less intense private efforts in finding a job.

Focussing on the key qualification variables, both better education and professional experience obviously increase the probability to be hired. Yet, the effects of higher formal education are stronger for insiders. Moreover, both Exact Qual and Less Qual are positive and highly significant. Thus, on first sight, overeducation does not appear to yield higher success probabilities. However, our interviews reveal that $H R$ and $D o E$ must agree on the job description before the opening is advertised. This description is used to calculate the workplace score (Grade). While $H R$ strictly oversees that the job description is not revised during the selection process, expectations concerning the relative scarcity of qualified applicants should nevertheless affect DoE's efforts to negotiate a higher score.

Since higher scores imply more generous salary ranges, there may therefore exist a second indirect effect of the applicants' qualification structure on the hiring probability. Specifically, the process of obtaining the workplace score may induce an endogeneity problem. Moreover, following Wooldridge (2002, p. 604), our estimates are unbiased, consistent, and asymptotically normal only if the decision to apply is random across the two groups. However, recall that entering an application requires the ability to use a computer and to set up an online account - both likely to be correlated with the individual's educational status. Hence, $H R$ 's on-site assistance in filing the online application may have induced a selection problem by encouraging relatively more applications by less educated insiders. 


\subsection{The IV-regression}

Both the endogeneity and the selection problem warrant the use of instrumental variables. Hence, we instrument Grade to account for the endogeneity of the job specification mechanism. Our interviews suggest that the three $D o E$-types within the firm (i.e., central administration, DoE staff positions, and technical support and services), face different labor market characteristics and, consequently, determine workplace scores such as to generate attractive salary ranges. Hence, the department-types qualify as adequate instruments. We set technical support and services as the reference department.

Furthermore, the number of applications by individuals who possess a higher than the minimum required educational degree - denoted Overeducated - proxies the firm's expectation concerning the scarcity of the respective personnel. Given the above, the decision to file an application should be a function of the recruiting channel reflecting an applicant's access to on-site assistance. Conditional on this covariate, the participation decisions should be independent between the two groups. Controlling for the recruiting channel in a Two-Stage Least Squares (2SLS) approach then appears sufficient to overcome this problem.

First, we perform the Hausman test for endogeneity to address the quality of our arguments above. Following Wooldridge (2002, p. 361 and p. 471), we insert the predicted residuals from the reduced form into the main regression equation and test whether the respective coefficient is statistically different from zero. The left hand side of Table 5 reports the results from the first stage. The respective $F$-statistic attains the value of $17.13^{20}$. Given that the Hausman test strongly rejects the null of no endogeneity, we next implement Murphy and Topel's (2002) approach to correct the standard errors and report the results for the linear probability model $(L P M)$ in the right-hand side of Table 5.

Further, in the reduced form (i.e. the left column of Table 5) the coefficient on the number of overeducated applicants is positive and highly significant. This finding confirms that $H R$ and $D o E$ agree on higher workplace scores when they expect more job candidates with higher educational degrees. ${ }^{21}$ However, to achieve a correct inference in the 2SLS framework, we check the correlation between the endogenous variable and

\footnotetext{
${ }^{20}$ To economize on space, we do not report the second step of the Hausman test.

${ }^{21}$ Within our sample, Grade varies in between 50 and 65 . Hence, one more overeducated applicant per job increases this score by 0.002 points.
} 
the instruments. The F-test for the null-hypothesis on the coefficients of Central Dept, DoE Dept, and Overeducated reveals a value of 376.92. Since this statistic follows a $\chi^{2}$-distribution with three degrees of freedom, the null hypothesis is strongly rejected. ${ }^{22}$ Thus, given both a partial $R^{2}$ of 0.7183 in the first-stage regression and this $F$-statistic, we conclude that our instruments are strong predictors of the endogenous variable. ${ }^{23}$

Comparing the partial effects of our $2 S L S-L P M$ model (Table 5) with those derived using $O L S$ (Table 4) and logit and probit (Table 6) reveals only small differences. ${ }^{24}$ With the exception of Grade that is instrumented, all other coefficients of the 2SLS regression preserve their signs and magnitudes. Moreover, the switch in sign for Grade does not indicate a lack of robustness. Rather, the presence of overeducated applicants constitutes a strong determinant of the workplace score. This argument then clearly supports the IV-approach. As before, more competition for the job - as measured by Applications and Applicant's Rc-decreases the probability to be hired. The former, however, enters via the recruiter's expectation when determining the workplace score (Grade).

Also, the coefficient on Less Qual becomes insignificant in the $2 S L S$ regression. Hence, accounting for the endogeneity of Grade, the undereducated do not exhibit higher success probabilities relative to the overeducated applicants anymore. Further, the marginal effects after logit and probit suggest that the effects of higher formal education and professional experience are even stronger for insiders. The marginal effects of the interaction variables are highly significant. Note that these results support our theoretical model since insiders possess lower educational degrees on average.

\subsection{Insider-outsider effects on the screening mechanism}

This subsection brings further evidence in favor of our testing hypotheses by looking at the impact of the different insider-outsider effects on the outcome of the recruiting

\footnotetext{
${ }^{22}$ Following Staiger and Stock (1997), the respective $F$-statistic should be greater than 10.83 .

${ }^{23}$ Baker et al. (1995). Also, we have experimented with other potential instruments and performed overidentification tests. However, the respective Lagrange Multiplier tests did not support the inclusion of any other instrument.

${ }^{24}$ We report the marginal effects using both logit and probit models mainly for comparison and robustness checks. Note, however, that interaction variables cannot be interpreted in the usual way in either logit or probit models. Following Ai and Norton (2003), the interaction effect must be calculated as $\partial^{2} \Phi(\cdot) /\left(\partial x_{1} \partial x_{2}\right)=\beta_{12} \Phi^{\prime}(\cdot)+\left(\beta_{1}+\beta_{12} x_{2}\right)\left(\beta_{2}+\beta_{12} x_{1}\right) \Phi^{\prime \prime}(\cdot)$.
} 
process. First, Table 7 considers three separate regressions across over ( $N=10923$ observations), adequately ( $N=10945$ observations), and less educated applicants ( $N=3362$ observations) where as before, Status denotes the dependent variable.

Due to space considerations, we only report the estimates for the key variables of interest. Several findings emerge. As expected, having work experience increases the probability of being hired both for insider and outsider applicants. However, the coefficient on Experience for insiders is statistically higher than that for outsiders across all types of applicants (for details, see the F-tests in Table 7). This finding confirms the implications of our theoretical and empirical results so far, showing that the "discount" rate applied to professional experience is lower for the insider applicants. In contrast, the coefficients on Education for insiders, while positive do not appear to be significant. The positive impact of outsiders' Education is strongest for the overeducated applicants. At the $1 \%$ level, the coefficient on outsiders' Education is statistically higher than that on the insiders' Education. For the less and adequately educated applicants, the impact of Education appears the same for both insider and outsider applicants. This fact further strengthens hypothesis $H 1$.

Table 8 concerns the testing of our second hypothesis. It reports the results of two separate regressions estimating the hiring probabilities for applicants who apply for jobs that require a High-School and a Bachelor diploma, respectively. These two types of jobs comprise the largest pools of applicants with 18,412 applications in the first and 10,923 applications in the second case. Hypothesis H2 appears verified as well. Thus, the coefficient on outsiders' Education is positive and significant for the $H S$-type jobs, while for the jobs that require a $B A$ degree, it does not appear to be statistically different from zero. This finding implies that that the overeducation effect on the group of outsider recruits increases with lower minimum educational standards advertised by the firm. Further, the positive impact of having work experience is statistically higher for insider than for outsider applicants (see the F-tests for details). These results align with previous findings in Table 3. More importantly, however, they clearly contradict the validity of the career mobility approach within the current context.

Finally, Table 9 further strengthens the second hypothesis by analyzing the predicted average hiring probabilities for over, adequately, and less educated applicants, across the two types of jobs. The LPM, logit, and probit estimates are almost identical. This analysis uses the LPM-results to derive the average hiring probabilities conditional on the advertised educational requirement for the full sample and a sample excluding all the 
insider applicants. Across the advertised degree requirements, the decrease in the predicted average hiring probabilities is largest for the less educated applicants. This result highlights again that, when competing for the same job, successful outsider recruits are characterized by higher educational attainments than insiders. Yet, the latter are generally more successful in becoming hired/promoted. Hence, our findings do not support the career mobility approach.

\subsection{Goodness of fit}

Since we are using firm-level data, an immediate question concerns whether our empirical results are also descriptive for the $H R$ 's activities and choices. Hence, we carry out the Hosmer-Lemeshow (1982) goodness-of-fit test. We divide our sample into six subsamples to compare observed and predicted counts of outcome events. This number of subgroups corresponds to the number of different minimum levels of education advertised: jobs which require (1) the ability to read and write, (2) a highschool diploma, (3) a postsecondary (i.e. two-year college) degree, (4) a bachelor's degree, (5) a master degree, and (6) a doctorate degree.

Thus, the first sextile corresponds to the 1/6-sample of applicants who are characterized by the lowest while the sixth sextile is defined for the subgroup with the highest probability to be hired. The Hosmer-Lemeshow $(H L)$ statistic is then computed as

$$
H L=\sum_{i=1}^{6}\left[\frac{(\text { observed counts }(i)-\text { predicted counts }(i))^{2}}{\text { predicted counts }(i)}\right] \text {. }
$$

If the null hypothesis of a "good fit" is true, this statistic is distributed $\chi^{2}$ with four degrees of freedom. The overall value of $H L$ of 4.77 implies that the null hypothesis of a "good fit" cannot be rejected with reasonable statistical significance.

Although the model therefore seems to fit well, there may still be a large number of cases where it fails to predict individual outcomes correctly. Given that a predicted hiring is defined by a predicted probability of being hired exceeding 0.5 , we compare this predicted with the actual outcome ("hired" or "not hired") for every applicant. In $96.4 \%$ of all cases the predictions are correct. Specifically, we correctly predict $99.82 \%$ of all non-hiring cases. However, a hiring decision is correctly predicted in only $6.75 \%$ of the respective cases. 
Of course, this share of correctly predicted hirings can be increased by lowering the cut-off probability defining this incidence. The functional relationship between the percentage of correctly predicted recruitments and the cut-off probability is denoted sensitivity. Yet, increasing the cut-off probability comes at the expense of increasing the probability of predicting a hiring when the actual outcome is "not hired". The respective functional relationship between the percentage of falsely predicted recruitments and the cut-off probability is denoted 1-specificity.

The so-called $R O C$-curve ${ }^{25}$ draws out the sensitivity-specificity trade-off and provides a benchmark: the predictive power of a model is better the higher the curve arches above the 45-degree line. The ROC-curve would coincide with this line if the model would both correctly and falsely predict $50 \%$ of all recruitments for all cut-off probabilities. In our case, the area under the ROC-curve is 0.7960 when we include all observations. However, we also calculate this curve using "out-of-sample"-forecasts. Specifically, we randomly exclude $10 \%$ of the successful applicants and re-estimate the model. Given the newly estimated coefficients, we compute the hiring probabilities of the recruits previously excluded. In this case, the area under the respective ROC-curve - depicted in Figure 1 - equals 0.7963 . The model thus exhibits rather strong predictive power. ${ }^{26}$

\section{Summary and policy discussion}

We analyze a standard employee selection model given two stylized institutional constraints: first, professional experience can perfectly substitute for a lack of formal education for insiders while this substitution is imperfect for applications from outside the firm. Second, due to increased legal risk, the respective "discount rate" applied to outsiders' professional experience increases with the advertised minimum educational requirement. The optimal selection policy then implies that the expected level of formal education is higher for outsider than for insider recruits. However, such recruits are only seemingly overeducated: in absence of these constraints restricting the signal value of education, the respective standards would be set higher and identically equal for both groups.

\footnotetext{
${ }^{25}$ I. e. the "Receiver Operating Characteristic" curve. See DeLong et al. (1988) for a discussion.

${ }^{26}$ Given a $\chi_{(1)}^{2}$-distribution, the test statistic of 2.78 indicates no significant difference (at a $5 \%$-level) between the full sample and the out-of-sample forecasts.
} 
Moreover, the difference in educational attainments between the two groups of recruits increases with lower educational job requirements. These insider-outsider effects are very specific to our theoretic approach and are strongly supported by our empirical results. At the same time, the results are also generally consistent with previous empirical work on the overeducation effect on the probability to be hired from the external labor market. Yet, in strong contrast with the career mobility approach as the alternative theoretic framework, overeducation does not increase the hiring probabilities - i. e. enhance the promotion chances - of insider recruits.

Our case concerns employee selection by a large US public employer that is subjected to constitutional restraints and self-regulated by manuals of fair employment practises. ${ }^{27}$ Currently, however, a set of similar regulations emerges in Europe: the Commission of the European Communities (2000) and the Council of Europe (2001) have initiated a process to establish the formal equivalence of educational degrees and professional experience gained in occupational training programs. This policy intends to foster lifelong learning and, mirroring the US disparate impact experience, to include population groups that are socially excluded from obtaining adequate education. The EU member states must establish systems of Accreditation of Prior Learning (APEL) that involve firms offering vocational training programs as well as non-governmental organizations representing such disadvantaged groups. ${ }^{28}$

The current states of implementation vary widely across the European countries. By virtue of the Validation des Acquis Professionneles (VAP) and the Validation des Acquis de l'Experience ( VAE) decrees, however, french employees can already obtain a perfect university degree equivalent certificate without attending university at all. ${ }^{29}$ Such legal equivalence rules ultimately constitute binding constraints on employee selection processes in all firms, public and private. Thus, the rate of substitution between formal education and professional experience should be equalized between insider and outsider applicants. This development will reduce the overeducation effect on hiring probabilities. However, it then also reduces the predictor value of formal education and, consequently, precision in recruitment processes.

\footnotetext{
${ }^{27}$ Obviously, we agree with Groeneveld and Hartog (2004) who caution that, unless reconfirmed regularly, case study results should not be generalized.

${ }^{28}$ See Davies (2003) for an overview of the origins and implemenation steps of this action plan.

${ }^{29}$ In contrast, the development in the United Kingdom is still much in the state of an initiating political debate, for instance. Hence, it may be particularly interesting, to refer to Gallagher and Feutrie (2003) as a combined French and Anglo-Saxon source for further insights.
} 


\section{References}

Abram, T.G. (1993). The Law, Its Interpretation, Levels of Enforcement, and Effect on Employer Behavior. American Economic Review, vol. 83, p. 62-66.

Ai, C. and E.C. Norton. (2003). Interaction Terms in Logit and Probit Models. Economics Letters, vol. 80, p. 123-129.

Anderson, N., F. Lievens, K. van Dam and A.M. Ryan. (2004) Future Perspectives on Employee Selection: Key Directions for Future Research and Practise. Applied Psychology: An International Review, vol. 53, p. 487-501.

Ashenfelter, O. and R. Oaxaca. (1987). The Economics of Discrimination. American Economic Review, vol. 77, p. 321-325.

Baker, R.M., J. Bound and D.A. Jaeger. (1995). Problems with Instrumental Variables Estimation When the Correlation between the Instruments and the Endogeneous Variable is Weak. Journal of the American Statistical Association, vol. 90, p. 443-450.

Bauer, T. (2002) Educational Mismatch and Wages: A Panel Approach. Economics of Education Review, vol. 21, p. 221-229.

Betsey, C.L. (1994). Litigation of Employment Discrimination under Title VII: the Case of African-American Women. American Economic Review, vol. 84, p. 98-102.

Carlson, R. (2005). Employment Law, New York, N.Y.: Aspen Publishers.

Chevalier, A. (2003). Measuring Over-Education. Economica, vol. 70, p. 509-531.

Chor, D. and R.B. Freeman. (2005). The 2004 Global Labor Survey: Workplace Institutions and Practices Around the World. Cambridge, Ma: National Bureau for Economic Research - NBER, Working Paper 11598.

Clardy, A. (2003). The Legal Framework of Human Resources Development, Part II: Fair Employment, Negligence, and Implications for Scholars and Practioners. Human Resources Development Review, vol. 2, p. 130-154.

Coate, S. and G. Loury. (1993). Antidiscrimination Enforcement and the Problem of Patronization. American Economic Review, vol. 83, p. 92-98. 
Commission of the European Communities. (2000). A Memorandum on Lifelong Learning. Luxembourg: OOPEC, Staff Working Paper, SEC 1832.

Council of Europe. (2001). Lifelong Learning and Social Cohesion: A New Challenge to Higher Education. Strasbourg: Council of Europe, Final Conference Report.

Dakin, S. and J. S. Armstrong. (1989). Predicting Job Performance: Comparison of Expert Opinions and Research Findings. International Journal of Forecasting, vol. 5, p. 187-194.

Davies, P. (2003). Widening Participation and the European Union: Direct Action Indirect Policy? European Journal of Education, vol. 38, p. 99-116.

DeLong, E.R., D.M. DeLong and D.L. Clarke-Pearson. (1988). Comparing the Areas under Two or More Correlated Receiver Operating Characteristic Curves: A NonParametric Approach. Biometrics, vol. 44, p. 837-845.

Duncan, G.J. and S.D. Hoffman. (1981). The Incidence and Wage Effects of Overeducation. Economics of Education Review, vol. 1, p. 75-86.

Freeman, R.B. (1976). The Overeducated American, New York: Academic Press.

Gallagher, J. and M. Feutrie. (2003). Recognising and Accrediting Informal and NonFormal Learning in Higher Education: An Analysis of the Issues Emerging from a Study of France and Scotland. European Journal of Education, vol. 38, p. 71-83.

Godard, J. (2002). Institutional Environments, Employer Practices, and States in Liberal Market Economies. Industrial Relations, vol. 41, p. 249-286.

Groeneveld, S. and J. Hartog. (2003). Overeducation, Wages and Promotions Within the Firm. Labour Economics, vol. 11, p. 701-714.

Groot, W. and H. Maasen van den Brink. (2000). Overeducation in the Labor Market: A Meta Analysis. Economics of Education Review, vol. 19, p. 149-158.

Gutman, A. (2003). On the Legal Front: Adverse Impact - Why Is It So Difficult to Understand. The Industrial-Psychologist, vol. 40, p. 42-50.

Gutman, A. (2004). On the Legal Front: Ground Rules for Adverse Impact. The Industrial-Psychologist, vol. 41, p. 109-119.

Han, C. and P.C.B. Phillips (2006). GMM with Many Moment Conditions. Econometrica, vol. 74, p. 147-192. 
Hartog, J. (2000). Over-Education and Earnings: Where Are We and Where Should We Go? Economics of Education Review, vol. 19, p. 131-147.

Holling, H. (1998). Utility Analysis of Personnel Selection: An Overview and Empirical Study Based on Objective Performance Methods. Methods of Psychological Research Online, vol. 3, p. 5-24.

Lemeshow, S. and Hosmer, D. W. (1982). A Review of Goodness of Fit Statistics for Use in the Development of Logistic Regression Models. American Journal of Epidemiology, vol. 115, p. 92-106.

Martin, W. (2005). KSA-Based Minimum Qualification Standards. Paper presented at the Mid-Atlantic Personnel Assessment Consortium - MAPAC, May 13, 2005.

Murphy, K. M. and Topel, R. H. (2002). Estimation and Inference in Two-Step Econometric Models. Journal of Business and Economic Statistics, vol. 20, 88-97.

Oyer, P. and S. Schafer. (2002). Litigation Costs and Returns to Experience. American Economic Review, vol. 92, p. 683-705.

Phillips, P.C.B. (2006). A Remark on Bimodality and Weak Instrumentation in Structural Equation Estimation. Econometric Theory, vol. 22, p. 947-960.

Robertson, I.T. and M. Smith. (2001). Personnel Selection. Journal of Occupational and Organizational Psychology, vol. 74, p. 441-472.

Sattinger, M. (1993). Assignment Models of Distribution of Earnings. Journal of Economic Literature, vol. 31, p. 851-880.

Schmidt, F.L. and J.E. Hunter. (1998). The Validity and Utility of Selection Methods in Personnel Psychology: Practical and Theoretical Implications of 85 Years of Research Findings. Psychological Bulletin, vol. 124, p. 262-274.

Sicherman, N. and O. Galor. (1990). A Theory of Career Mobility. Journal of Political Economy, vol. 98, p. 169-192.

Spence, M. (1973). Job Market Signaling. Quarterly Journal of Economics, vol. 87, p. $355-374$.

Staiger, D. and Stock, J. H. (1997). Instrumental Variables Regression with Weak Instruments. Econometrica, vol. 65, p. 557-586. 
Thurow, L. C. (1975). Generating Inequality: Mechanisms of Distribution in the US Economy. New York, N.Y.: Basic Books.

US Equal Employment Opportunity Commission - EEOC, Civil Service Commission, (1978). Uniform Guidelines on Employee Selection Procedures. Washington, D.C.: Federal Register, Vol. 43.

US Equal Employment Opportunity Commission - EEOC. (2006). EEOC Compliance Manual, Section 15: Race \& Color Discrimination, Washington, D.C.: EEOC 4/9/2006, Directives Transmittal No. 915.003.

Welch, F. (1981). Affirmative Action and Its Enforcement. American Economic Review, vol. 71, p. 127-133.

Wooldridge, J. M. (2002). Econometric Analysis of Cross Section and Panel Data. Cambridge, Ma.: MIT Press. 


\section{Appendix A: Variables Description}

- The set of dependent variables

- Status $=$ indicates hiring status: 1 if hired, 0 if not hired

- Variables which concern the recruiting channel

- SEO = is 1 if the recruiting channel is "State Employment Office"; 0 elsewhere

- JNU $=$ is 1 if the recruiting channel is "A job notice sent to my organization"; 0 elsewhere

$-\mathrm{DCD}=$ is 1 if the recruiting channel is "Direct contact from department"; 0 elsewhere

- ORC $=$ is 1 if the recruiting channel is "Other Recruiting Channels"; 0 elsewhere

- NWAd $=$ is 1 if the recruiting channel is print-ad type - "Newspaper Advertisement, Professional journal, newsletter, list-serve, or registry"; 0 elsewhere

- IntReffered $=$ is 1 if the recruiting channel is "Referred by a current employee"; 0 elsewhere

- WebRC $=$ is 1 if the recruiting channel is web-based; 0 elsewhere

- Insiders $=$ DCD \& IntReffered

- Variables which concern the type of each department where job positions are opened

- Centr. Admin. = is 1 if the job is in the Central Administration; 0 elsewhere

- DoE Admin. = is 1 if the job is in a Department of Employment; 0 elsewhere

- TechDept $=$ is 1 if job is in the technical department; 0 elsewhere

- Variables which concern job specifications

- Grade $=$ numerical value determined on the basis of six factors and it indicates the payment range of a position title. It increases with job requirements.

- $\mathrm{EEO}=$ stands for Equal Employment Opportunity. It has a value of 10 for executive and managerial positions and increases up to 70 for service and maintenance positions. 
- FLSA = indicates the Fair Labor Standard Status; it is 1 if employees are exempt (i.e. do not get paid if they do over time work) and 0 if they are not exempt (i.e. they are paid if they work overtime)

- JobType $=$ it is a ranking variable that takes value in between 1 and $6 ; 1$ is the lowest ranked and corresponds to Contingent/On-Call (No Benefits) while highest job type is Regular - Full-Time (Benefits Eligible)

- Quantitative variables regarding each type and number of applicants

- Applications $=$ total number of applications per position title

- Less Qual. = dummy that is 1 if undereducated; 0 otherwise

- Exact Qual. = dummy that is 1 if adequately educated; 0 otherwise

- Over Qual. = dummy that is 1 if overeducated; 0 otherwise

- Overqualified $=$ number of overeducated applicants for each position title

- Appl.'s Rc = number of applicants per recruiting channel

- Variables which are applicants' characteristic

- Age $=$ Each applicant's age; Age Sq. = square of Age

- Experience $=$ is 1 if the applicant has work experience and 0 if he does not

- Exp. Ins. = interaction variable between Experience and Insiders

- Education $=$ Ranking variable that goes from 0 (i.e. 1st grade) until the highest level of 19 (i.e. doctorate); Educ. Sq. = square of Education

- Educ. Ins. = interaction variable between Education and Insiders.

- Sex $=1$ if Male, 0 if Female

- NonWhite $=$ is 1 if White/Non-Hispanic; 0 elsewhere. 


\section{Appendix B: Tables and Figures}

Table 1: Descriptive statistics of the online-recruitment system

\begin{tabular}{|r|r|r|}
\hline Total number of applications & 33780 & $100 \%$ \\
\hline Qualified applicants forwarded to departments & 26641 & $78.86 \%$ \\
\hline Disqualified applicants & 4469 & $13.22 \%$ \\
\hline Applications cancelled & 828 & $2.45 \%$ \\
\hline Applications withdrawn & 837 & $2.47 \%$ \\
\hline Applications filed but failed to maintain contact & 1005 & $2.97 \%$ \\
\hline Number of jobs filled using on-line system & 1244 & $3.68 \%$ \\
\hline
\end{tabular}

Table 2: Educational attainments of applicants and recruits

\begin{tabular}{|r|r|r|r|r|r|r|r|r|r|}
\hline Year & Doct. & Mast. & Bach. & Some Coll. & Highsch. & Some High. & GED & n.a. & Total \\
\hline & All applicants & & & & & & & & \\
\hline 2003 & 135 & 883 & 2208 & 2615 & 789 & 42 & 116 & 13 & 6801 \\
\hline 2004 & 274 & 2068 & 4031 & 3850 & 1031 & 55 & 165 & 9 & 11483 \\
\hline 2005 & 410 & 2271 & 4648 & 4804 & 1338 & 30 & 156 & 9 & 13666 \\
\hline 2006 & 30 & 255 & 714 & 589 & 201 & 8 & 32 & 1 & 1830 \\
\hline & Recruits & & & & & & & & \\
\hline 2003 & 7 & 24 & 51 & 84 & 29 & 1 & 3 & 0 & 199 \\
\hline 2004 & 13 & 73 & 158 & 143 & 57 & 2 & 6 & 0 & 452 \\
\hline 2005 & 19 & 84 & 181 & 180 & 50 & 1 & 7 & 0 & 522 \\
\hline 2006 & 1 & 16 & 29 & 20 & 5 & 0 & 0 & 0 & 71 \\
\hline
\end{tabular}


Table 3: Insider-Outsider Distinction

\begin{tabular}{|c|c|c|c|c|}
\hline Use of recruitment channels & & & & \\
\hline DCD & $1.38 \%$ & & & \\
\hline IR & $10.02 \%$ & & & \\
\hline WebRc & $77.20 \%$ & & & \\
\hline NwAd & $7.76 \%$ & & & \\
\hline JNU & $0.39 \%$ & & & \\
\hline SEO & $0.24 \%$ & & & \\
\hline ORC & $3.00 \%$ & & & \\
\hline \multicolumn{5}{|l|}{ Recruits: Outsiders vs Insiders } \\
\hline Hired applicants & (\%) percent of all hired & IR $(\%)$ & $\operatorname{DCD}(\%)$ & Insiders ( $\%$ of $)$ \\
\hline Undereducated & 8.03 & 20 & 31 & 51 \\
\hline Adequately educated & 33.52 & 15.58 & 24.7 & 40.28 \\
\hline Overeducated & 58.44 & 13.75 & 29.02 & 42.77 \\
\hline
\end{tabular}


Table 4: OLS Regression

OLS: $\quad\left(\mathrm{R}^{2}=0.0879\right)$

\begin{tabular}{llc}
\hline \hline Dep. Variable: Status & Coefficient & (Std. Err.) \\
\hline \hline Grade & $-.002^{* * *}$ & $(.001)$ \\
\hline Applications & $-.001^{* *}$ & $(.000)$ \\
\hline Appl.'s Rc & $-.001^{* * *}$ & $(.000)$ \\
\hline Exact Qual. & $.012^{* * *}$ & $(.003)$ \\
\hline Less Qual. & $.011^{* * *}$ & $(.004)$ \\
\hline EEO & .001 & $(.001)$ \\
\hline FLSA & .001 & $(.002)$ \\
\hline Job Type & $-.026^{* * *}$ & $(.002)$ \\
\hline SEO & $-.526^{* * *}$ & $(.100)$ \\
\hline JNU & -.003 & $(.025)$ \\
\hline ORC & $.038^{* * *}$ & $(.012)$ \\
\hline Web Rc. & $.619^{* * *}$ & $(.093)$ \\
\hline Insiders & .007 & $(.028)$ \\
\hline Age & -.001 & $(.001)$ \\
\hline Age Sq. & $.001^{*}$ & $(.000)$ \\
\hline Experience & $.014^{* * *}$ & $(.002)$ \\
\hline Exp. Ins. & $.106^{* * *}$ & $(.012)$ \\
\hline Education & $.009^{* * *}$ & $(.003)$ \\
\hline Educ. Sq. & $-.001^{*}$ & $(.000)$ \\
\hline Educ. Ins. & $.005^{* *}$ & $(.002)$ \\
\hline Sex & $-.004^{*}$ & $(.002)$ \\
\hline Non White & $-.018^{* * *}$ & $(.002)$ \\
\hline Const. & $.258^{* * *}$ & $(.054)$ \\
\hline otes: Robust standard errors in parenthesis; Significance at the 10\% level; & \\
\hline
\end{tabular}

Notes: Robust standard errors in parenthesis; ${ }^{*}$ Significance at the $10 \%$ level;

${ }^{* *}$ Significance at the $5 \%$ level; ${ }^{* *}$ Significance at the $1 \%$ level; $N=33780$ observations 
Table 5: IV-regression: The LP-model

\begin{tabular}{|c|c|c|c|c|c|}
\hline $\mathbf{1}^{\text {st }}$ Stage: & $\left(\mathrm{R}^{2}=0.0879\right)$ & & $\overline{2}^{\text {nd }}$ Stage: & $\left(\mathrm{R}^{2}=0.0879\right)$ & \\
\hline Grade & Coefficient & (Std. Err.) & Status & Coefficient & (Std. Err.) \\
\hline- & - & - & Grade & $.010^{* * *}$ & "(.002) \\
\hline Centr. Admin. & $-.765^{* * *}$ & $(.027)$ & - & -- & \\
\hline DoE Admin. & $-.684^{* * *}$ & $(.027)$ & - & -- & \\
\hline Overeducated & $.002^{* * *}$ & $(.000)$ & - & -- & \\
\hline Applications & $-.002^{* * *}$ & $(.000)$ & Applications & .001 & $(.001)$ \\
\hline Appl.'s Rc & .001 & $(.001)$ & Appl.'s Rc & $-.001^{* * *}$ & $(.000)$ \\
\hline Exact Qual. & $.328^{* * *}$ & $(.021)$ & Exact Qual. & $.010^{* * *}$ & $(.003)$ \\
\hline Less Qual. & $.76^{* * *}$ & $(.034)$ & Less Qual. & .004 & $(.004)$ \\
\hline EEO & $-.109^{* * *}$ & $(.001)$ & EEO & $.001^{* * *}$ & $(.000)$ \\
\hline FLSA & $.243^{* * *}$ & $(.050)$ & FLSA & $-.004^{*}$ & $(.002)$ \\
\hline Job Type & $.435^{* * *}$ & $(.008)$ & Job Type & $-.032^{* * *}$ & $(.002)$ \\
\hline SEO & -.371 & $(.290)$ & SEO & $-.519^{* * *}$ & $(.100)$ \\
\hline JNU & .047 & $(.118)$ & JNU & -.003 & $(.025)$ \\
\hline ORC & .034 & $(.056)$ & ORC & $.038^{* * *}$ & $(.012)$ \\
\hline Web Rc. & .118 & $(.292)$ & Web Rc. & $.616^{* * *}$ & $(.093)$ \\
\hline Insiders & .164 & $(.131)$ & Insiders & .005 & $(.028)$ \\
\hline Age & $.047^{* * *}$ & $(.005)$ & Age & $-.001^{*}$ & $(.001)$ \\
\hline Age Sq. & $-.001^{* * *}$ & $(.000)$ & Age Sq. & $.001^{* *}$ & $(.000)$ \\
\hline Experience & $-.103^{* * *}$ & $(.015)$ & Experience & $.015^{* * *}$ & $(.002)$ \\
\hline Exp. Ins. & .066 & $(.047)$ & Exp. Ins. & $.105^{* * *}$ & $(.012)$ \\
\hline Education & $-.320^{* * *}$ & $(.036)$ & Education & $.012^{* * *}$ & $(.004)$ \\
\hline Educ. Sq. & $.015^{* * *}$ & $(.001)$ & Educ. Sq. & $-.001^{* * *}$ & $(.000)$ \\
\hline Educ. Ins. & $-.018^{* * *}$ & $(.008)$ & Educ. Ins. & $.005^{* *}$ & $(.002)$ \\
\hline Sex & $.251^{* * *}$ & $(.018)$ & Sex & $-.008^{* * *}$ & $(.003)$ \\
\hline Non White & $-.084^{* * *}$ & $(.015)$ & Non White & $-.017^{* * *}$ & $(.002)$ \\
\hline Const. & $58.592^{* * *}$ & $(.315)$ & Const. & $-.410^{* *}$ & $(.168)$ \\
\hline
\end{tabular}

Notes: ${ }^{*}$ Significance at the $10 \%$ level; ${ }^{* *}$ Significance at the $5 \%$ level;

*** Significance at the $1 \%$ level; $N=33780$ observations 
Table 6: Logit and Probit Regressions: Marginal Effects

\begin{tabular}{|c|c|c|c|c|c|}
\hline Logit & & & Probit & & \\
\hline Status & $\Delta y / \Delta x$ & (Std. Err.) & Status & $\Delta y / \Delta x$ & (Std. Err.) \\
\hline Grade & $.004^{* *}$ & $(.002)$ & Grade & $.005^{* *}$ & $(.002)$ \\
\hline Applications & .001 & $(.001)$ & Applications & .001 & $(.001)$ \\
\hline Appl.'s Rc & $-.001^{* * *}$ & $(.000)$ & Appl.'s Rc & $-.001^{* * *}$ & $(.000)$ \\
\hline Exact Qual. & $.009^{* * *}$ & $(.002)$ & Exact Qual. & $.011^{* * *}$ & $(.002)$ \\
\hline Less Qual. & .002 & $(.003)$ & Less Qual. & .002 & $(.004)$ \\
\hline EEO & $.001^{* * *}$ & $(.000)$ & EEO & $.001^{* * *}$ & $(.000)$ \\
\hline FLSA & -.001 & $(.001)$ & FLSA & -.001 & $(.001)$ \\
\hline Job Type & $-.011^{* * *}$ & $(.001)$ & Job Type & $-.014^{* *}$ & $(.001)$ \\
\hline SEO & $-.022^{* * *}$ & $(.001)$ & SEO & $-.022^{* * *}$ & $(.001)$ \\
\hline JNU & .012 & $(.012)$ & JNU & .001 & $(.010)$ \\
\hline ORC & $.038^{* * *}$ & $(.011)$ & ORC & $.027^{* * *}$ & $(.009)$ \\
\hline Web Rc. & $.305^{* * *}$ & $(.047)$ & Web Rc. & $.375^{* * *}$ & $(.048)$ \\
\hline Insiders & $.037^{*}$ & $(.020)$ & Insiders & $.032^{*}$ & $(.020)$ \\
\hline Age & .001 & $(.001)$ & Age & .001 & $(.001)$ \\
\hline Age Sq. & .001 & $(.001)$ & Age Sq. & .001 & $(.001)$ \\
\hline Experience & $.014^{* * *}$ & $(.002)$ & Experience & $.015^{* * *}$ & $(.002)$ \\
\hline Exp. Ins. & $.057^{* *}$ & $(.025)$ & Exp. Ins. & $.056^{* *}$ & $(.022)$ \\
\hline Education & $.011^{* * *}$ & $(.003)$ & Education & $.013^{* * *}$ & $(.003)$ \\
\hline Educ. Sq. & $-.001^{* * *}$ & $(.000)$ & Educ. Sq. & $-.001^{* * *}$ & $(.000)$ \\
\hline Educ. Ins. & $.058^{* * *}$ & $(.018)$ & Educ. Ins. & $.043^{* * *}$ & $(.012)$ \\
\hline Sex & $-.003^{* *}$ & $(.001)$ & Sex & $-.004^{* *}$ & $(.001)$ \\
\hline Non White & $-.011^{* * *}$ & $(.001)$ & Non White & $-.013^{* * *}$ & $(.001)$ \\
\hline
\end{tabular}


Table 7: Education Effects Across the Three Types of Applicants

\begin{tabular}{|c|c|c|c|c|c|c|}
\hline \multirow{2}{*}{$\begin{array}{l}\text { Applicants Type: } \\
\text { Dep. Variables: }\end{array}$} & \multicolumn{2}{|c|}{ Overeducated } & \multicolumn{2}{|c|}{ Adequately Educated } & \multicolumn{2}{|c|}{ Less Educated } \\
\hline & $\begin{array}{l}\text { Status } \\
\text { Coefficient }\end{array}$ & $\begin{array}{c}N=19473 \\
\text { (Std. Err.) }\end{array}$ & $\begin{array}{l}\text { Status } \\
\text { Coefficient }\end{array}$ & $\begin{array}{c}N=10945 \\
\text { (Std. Err.) }\end{array}$ & $\begin{array}{l}\text { Status } \\
\text { Coefficient }\end{array}$ & $\begin{array}{c}N=3362 \\
\text { (Std. Err.) }\end{array}$ \\
\hline Experience & $.012^{* * *}$ & $(.003)$ & $.020^{* * *}$ & $(.004)$ & $.010^{*}$ & $(.006)$ \\
\hline Exp. Ins. & $.090^{* * *}$ & $(.016)$ & $.095^{* * *}$ & $(.021)$ & $.071^{* *}$ & $(.032)$ \\
\hline Educ. & $.036^{* * *}$ & $(.011)$ & .017 & $(.016)$ & $.010^{*}$ & $(.005)$ \\
\hline Educ. Ins. & .005 & $(.003)$ & .004 & $(.003)$ & .006 & $(.005)$ \\
\hline Outsiders $=$ Insiders & F-stat & p-value & F-stat & p-value & F-stat & p-value \\
\hline Experience & 22.20 & 0.0000 & 11.60 & 0.0007 & 3.31 & 0.0691 \\
\hline Education & 6.18 & 0.0129 & 0.63 & 0.4268 & 0.13 & 0.7154 \\
\hline
\end{tabular}

Table 8: Education Effects across Jobs with High-School and Bachelor Degrees Required

\begin{tabular}{lcccc}
\hline \hline \multirow{2}{*}{ Dep. Variables: } & \multicolumn{2}{c}{ High-School Degree } & \multicolumn{2}{c}{ Bachelor Degree } \\
& Status & N=18412 & Status & N=10923 \\
& $.013^{* * *}$ & $(.003)$ & $.012^{* * *}$ & $(.003)$ \\
\hline Experience & $.130^{* * *}$ & $(.017)$ & $.055^{* * *}$ & $(.019)$ \\
\hline Exp. Ins. & $.017^{*}$ & $(.009)$ & -.005 & $(.006)$ \\
\hline Education & $.006^{*}$ & $(.003)$ & .007 & $(.005)$ \\
\hline Educ Ins. & F-stat & p-value & F-stat & p-value \\
\hline \hline Outsiders=Insiders & 43.78 & 0.0000 & 4.80 & 0.0284 \\
\hline Experience & 1.23 & 0.2678 & 1.88 & 0.1706
\end{tabular}

Notes: Robust standard errors in parenthesis; ${ }^{*}$ Significance at the $10 \%$ level; ${ }^{* *}$ Significance at the $5 \%$ level; *** Significance at the $1 \%$ level. 
Table 9: Predicted hiring probabilities with and without insiders

\begin{tabular}{rccc}
\hline Hiring Prob. of & Overeducated & Adequately Educated & Less Educated \\
\hline LPM & $3.73 \%$ & $3.80 \%$ & $2.97 \%$ \\
\hline Logit & $3.73 \%$ & $3.80 \%$ & $2.97 \%$ \\
\hline Probit & $3.72 \%$ & $3.83 \%$ & $2.95 \%$ \\
\hline With insiders taken into account & & & \\
\hline High-School Diploma required & $3.02 \%$ & $1.19 \%$ & $0.03 \%$ \\
\hline Bachelors required & $0.42 \%$ & $1.78 \%$ & $0.89 \%$ \\
\hline \hline Without insiders taken into account & & & \\
\hline High-School Diploma required & $1.99 \%$ & $0.87 \%$ & $0.40 \%$ \\
\hline Bachelors required & $0.23 \%$ & $1.09 \%$ & \\
\hline \% Change & & & $-51.62 \%$ \\
\hline \% High-School & $-34.17 \%$ & $-27.25 \%$ & $-55.24 \%$ \\
\hline \hline
\end{tabular}




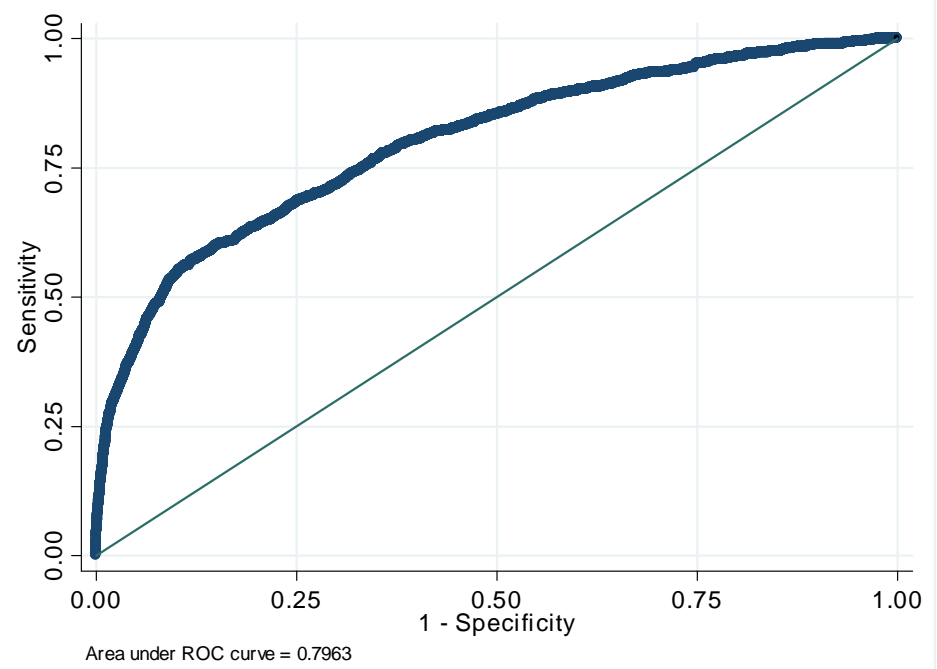

Figure 1: ROC Curve 